\title{
Regional diagnostic panels for aeroallergens in Canada
}

\author{
Joshua Young ${ }^{*}$, Robert Erskine, Tricia Moore, Greg Plunkett \\ From Canadian Society of Allergy and Clinical Immunology Annual Scientific Meeting 2013 \\ Toronto, Canada. 3-6 October 2013
}

\section{Background}

Prevalence of allergenic plants varies by geographic region and climate, which affects the level of allergen exposure experienced by patients in different parts of the country. Because of these variations in exposure it is recommended that allergy practices use customized regional diagnostic panels based on the prevalence and significance of various aeroallergens. However, gathering this information can be difficult for new physicians. The purpose of these recommendations is to provide a foundation for new physicians to begin building a custom aeroallergen panel for all regions of Canada.

\section{Methods}

Clinical, geographical and botanical references were evaluated and compiled to determine the prevalence and impact of various aeroallergens across Canada. These recommendations were discussed with regional allergy practices and other clinical authorities for consensus on recommendations.

\section{Results}

Aeroallergen recommendations were compiled into a prevalence map and table that was organized by the major geographic regions of Canada. Allergens were categorized as (1) high allergenicity \& high prevalence, (2) high allergenicity \& low prevalence, (3) low allergenicity \& high prevalence, or (4) low allergenicity \& low prevalence. A significant degree of allergen similarity across all regions was recognized although specific differences in species selection and general distribution patterns were identified for each region.

\section{Conclusions}

Gathering clinical and botanical prevalence data for aeroallergens across different regions can be time consuming and difficult. These recommendations were compiled from many years of industry experience working with allergy specialists across the country and were verified by the literature. It is hoped that this knowledge can provide a foundation for new physicians trying to understand which aeroallergens to target for allergy diagnostic panels specific to their region.

Published: 3 March 2014

doi:10.1186/1710-1492-10-S1-A17

Cite this article as: Young et al:: Regional diagnostic panels for aeroallergens in Canada. Allergy, Asthma \& Clinical Immunology 201410 (Suppl 1):A17.

* Correspondence: joshua.young@alk.net

Submit your next manuscript to BioMed Central and take full advantage of:

- Convenient online submission

- Thorough peer review

- No space constraints or color figure charges

- Immediate publication on acceptance

- Inclusion in PubMed, CAS, Scopus and Google Scholar

- Research which is freely available for redistribution
( Bīomed Central

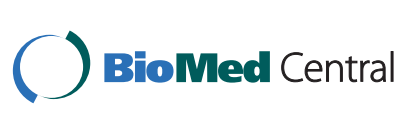

